\title{
A medio camino. Intertextos entre la literatura y el derecho. Diego Falconí Trávez (ed.) (2016). Valencia: Tirant Humanidades
}

\author{
María Susana Bastidas Tamayo \\ Colegio de Jurisprudencia, USFQ
}

Recuerdo con claridad el momento crucial en el que leí una de las múltiples enseñanzas del starets Zózima, personaje de la novela Los hermanos Karamazov de Dostoievski. En esta obra, Zózima hace alusión a la labor del juez como agente que decide respecto de la culpabilidad de un tercero y, tras un profundo análisis filosófico, llega a afirmar de manera rotunda la imposibilidad de juzgar al acusado sin antes reconocer nuestros propios crímenes (Dostoievski, 2009, p. 442). En realidad, la presencia de las normas de una sociedad determinada es una constante en toda obra literaria. Fue probablemente en aquel instante que me fue posible comprender la estrecha relación que la literatura guarda con el derecho y la influencia a la que mutuamente pueden estar expuestas dichas áreas del conocimiento.

La conexión íntima entre ambas ramas del saber no ha pasado desapercibida por teóricos literarios y académicos del derecho, quienes han pretendido esbozar ciertos parámetros que asemejan o diferencian a la literatura del derecho con la finalidad de dar una mayor claridad en esta zona fronteriza. Gradualmente, y acaso por motivaciones distintas, el estudio del derecho y la literatura ha cobrado una fuerza imparable durante las últimas décadas y, en lugar de agotar el tema, ha abierto al debate un sinnúmero de preguntas teóricas. Lo cierto es que, tal como lo manifiesta Richard A. Posner, si bien esta rama del pensamiento no es nueva, definitivamente permite adentrarse en un tema cuya relevancia radica en la contribución de un entendimiento más profundo, ya sea tanto de la literatura como del derecho (1986, p. 1351).

En este sentido, A medio camino. Intertextos entre la literatura y el derecho (2016) resulta ser un estudio teórico realizado en conjunto por un grupo de investigadores que tienen como objetivo - como señala el editor del libro- "dar cuenta de las productivas relaciones que se han gestado en estas décadas y que han permitido transgredir las fronteras de escritura (y lectura) que se han establecido entre textos jurídicos y literarios" (p. 18). Solamente de esta manera, el abismo existente entre un texto jurídico y un texto literario puede llegar a disiparse, con el fin de evitar caer en maniqueísmos que no tienen cabida en el mundo contemporáneo. Acaso el derecho manifestado en una sentencia dictada por un juez pueda ser analizado como literatura o la literatura pueda ser la representación de una realidad que pretende evocar un ordenamiento jurídico determinado.

La propuesta de Falconí Trávez en esta obra dialoga con la deconstrucción de Derrida, cuya finalidad última era la de evitar caer en el logocentrismo. En este caso, la negación de que el polo literatura o el polo derecho se conviertan en el centro de un sistema (Selden, 2000 , p. 104) y que se critique únicamente a través de uno de estos lentes es fundamental en este volumen.

Es por esta razón que el título del libro reseñado sugiere un encuentro entre el derecho y la literatura, un encuentro a medio camino que permita al lector abrir la mente a una nueva perspectiva. No es posible ignorar que la frase del título proviene de la aclamada novela El proceso (1925) de Franz Kafka, que manifiesta la cercanía existente entre las humanidades y el derecho, entre la casa del pintor y el juzgado. En $A$ medio camino. Intertextos entre la literatura y el derecho, el camino medio o el punto de colisión está representado a través del 
intertexto, herramienta que permite reconocer la "presencia efectiva de un texto en otro texto" (Genette, 1989: 10). Es de esta manera que los colaboradores de este volumen recurren a textos cuyo análisis puede realizarse desde el punto de vista de la literatura o del derecho.

Integrado por quince artículos, A medio camino. Intertextos entre la literatura y el derecho aborda temas variados y actuales que se circunscriben en su mayoría a la realidad latinoamericana de los últimos años; aunque, en el libro, está presente también una mirada europea representada en los trabajos de Julia Lewandowska, Santiago Montobbio, Giuseppa Ottimofiore, María Dolores Talón Antón y Meri Torras Francés. Podría afirmarse que, adicionalmente al aporte realizado a la rama del saber del derecho y la literatura, esta obra resuena en los oídos del lector como una narración cruda de la realidad que nuestras sociedades viven día a día, una denuncia a la corrupción, a la discriminación y a la injusticia. Normas transgredidas, leyes denunciadas, el ordenamiento jurídico infringido y la identidad de nuevos sujetos jurídicos que no han sido plenamente reconocidos por el derecho aparecen en un entramado de narraciones a lo largo del libro.

Cuestión muy aparte resultan los poemas seleccionados para conformar parte de este volumen. Cada uno de los textos de los poetas Orozco y Montobbio se ubica estratégicamente como un abrebocas del ensayo académico que precede. No obstante, no deben ser analizadas de manera superficial por el lector, como si se tratara de una ola refrescante que permite el cambio de temática del siguiente texto. En realidad, los poemas escogidos para $A$ medio camino. Intertextos entre la literatura y el derecho comparten un lenguaje retórico que es muestra latente de las difíciles, y a veces hasta inexistentes, fronteras marcadas entre el derecho y las humanidades, entre la norma y el arte. De manera precoz y sutil, los poetas invitan al lector a adentrarse en versos que emergen como un ejemplo más de la posibilidad y del medio camino que las dos disciplinas pueden entramar. El discurso narrativo invita al lector a cuestionarse si en realidad puede haber lugar para una falta de "literalidad de fenómenos no literarios", en este caso, el derecho (Culler, 2000, p. 30).

Un aspecto que resalta a primera vista es la estructuración del libro. En una búsqueda de orden, Falconí Trávez recurre a una división temática de los artículos, a través de capítulos que buscan encerrar cierto tipo de línea argumentativa. El orden, en realidad, resulta indiferente en cuanto los ensayos pueden ser leídos de manera indistinta por el lector. No obstante, para efectos prácticos la división en capítulos resulta una guía útil para investigadores que pretendan ahondar su conocimiento en un tema determinado.

El primer capítulo: "En la frontera de lo justo. Los jueces al estrado", va de la mano del magistrado como agente administrador de justicia y reposa específicamente en la idea del juicio como estructura que determina el destino del sujeto. A lo largo de esta sección, André Karam Trindade pretende exponer la relevancia del juicio como institución civilizadora en una sociedad completamente ajena a las normas, al orden o a la ley. El intertexto, expresado en la obra Gran Sertón: veredas (1956), brinda al lector la oportunidad de comprender la "histórica necesidad de juzgar" las acciones del otro con el fin de limitar el poder del Otro. Una mención especial merece, a mi juicio, el artículo de Andrés Botero. A través de la filosofía del derecho y tomando como punto de partida la tragedia de Sófocles, Edipo Rey, el autor realiza un análisis comparativo entre la obra mencionada y la producción audiovisual Edipo Alcalde (1996). El aporte radica en la posibilidad de replantearse la aplicación de la corriente del iusnaturalismo cosmológico en circunstancias contemporáneas. Por su lado, Amalia Amaya realiza un profundo adentramiento respecto de la importancia del juez ejemplar como prototipo de enseńanza para generaciones futuras de magistrados.

La figura del autor ha sido tema debatido en los salones de la teoría literaria desde hace ya décadas. Pensadores como Roland Barthes, Michel Foucault e Ian Ward han procurado 
encontrarle un sentido a la función-autor y al rol del autor dentro de la obra. El segundo capítulo de este libro, "El derecho a ser autor: puentes, lagunas y abismos entre escritura y cuerpo", agrupa ensayos académicos que buscan dar una respuesta desde la literatura y el derecho al autor, su derecho para con la obra y su protagonismo dentro de la creación literaria. Jorge Roggero realiza un análisis del complejo tema de la "muerte del autor" o de un "derecho sin autor" en el que la muerte del autor implica "el nacimiento de la interpretación". Por su parte, Merri Tomas Francés se adentra en el análisis de la propiedad intelectual y del manejo de autores y editores en el mundo contemporáneo, remitiendo al lector a un caso específico de ciertas cartas escritas por mujeres, quienes por no ser sujetos del derecho no figuraron como autoras de sus creaciones. Este análisis, sumamente interesante y válido desde la crítica feminista, acerca a la audiencia a una realidad histórica desconsoladora para aquellos sujetos que no eran considerados como tal dentro del ordenamiento jurídico. En esta línea argumentativa, el ensayo de Julia Lewadowska tiene por enfoque el rol de la mujer como autora de paratextos y el monopolio masculino de las artes imperante en la antigüedad.

La literatura ha sido empleada como una herramienta de desfogue para sujetos o acaso quasi sujetos. Lo verdaderamente interesante del tercer capítulo de este volumen, "Modos de narrar que (des)conectan con la ley", radica en el enfoque de los investigadores, que busca la apertura de la persiana del ordenamiento jurídico para vincularlo al comportamiento de los personajes dentro de los parámetros establecidos. De la mano de Macarena Areco Morales es posible analizar la institución de la confesión, empleada como prueba rotunda en el derecho y, al mismo tiempo, analizada como un proceso de curación y hasta de salvación (dentro de lo posible). Despertando tristes recuerdos de las dictaduras militares de Chile y Argentina, Areco Morales da lugar a la inclusión de voces femeninas de la literatura con el fin de analizar la importancia o distinción que el género evoca/ba en aquellos tiempos. Como parte de este capítulo, los trabajos de tres estudiantes se hacen presentes. En su artículo, Miguel Molina Díaz y Alejandro Veiga Expósito realizan un análisis de la novela Adrif's Book cuyo propósito radica en la indeterminación del sujeto jurídico/literario, que se ve plasmado directamente en la indeterminación del género de la obra y del personaje principal de esta. Yendo un poco más allá, este ensayo académico ofrece al lector la oportunidad de cuestionarse la falta de aceptación de ciertos sujetos dentro del ordenamiento jurídico. Marianné Núnez Núñez y Rosa Núñez Pacheco, por otra parte, realzan la figura del fiscal Chacaltana de las obras del escritor Santiago Rocangliolo. El artículo es un reflejo de la parodia empleada como un género de denuncia que a gritos desesperados acusa el sistema judicial peruano.

El cuarto capítulo del libro, "Desencuentros de la violencia, encuentros con el sujeto", abarca ensayos académicos que denuncian la violencia creada por el ordenamiento jurídico hacia ciertos personajes de la ficción literaria. Así, María Dolores Talón Antón admite la existencia de "comportamientos que son claras manifestaciones de violencia de género" al referirse expresamente a las mujeres como sujetos vulnerables de atentados contra la dignidad. Este análisis permite al lector retrotraer el tiempo a los años de vida del escritor del Siglo de Oro español, Lope de Vega, en un intento de aclarar si el literato era un defensor de los derechos humanos de la mujer. En su artículo, Ingrid Urgelles Latorre se adentra en el intrincado tema de la "violencia jurídica", como aquella permisión por parte del ordenamiento jurídico para ejercer actos de violencia hacia determinados personajes que pueden resultar una amenaza al sistema. Finalmente, a través de la exposición del ecuatoriano Rámiro Ávila es posible apreciar la institución carcelaria ya sea en el espectro de la realidad como en la esfera metafórica. La libertad es una constante en este artículo que pretende replantear la verdadera finalidad de la reclusión.

Para finalizar, Falconí Trávez ha dedicado el último capítulo del volumen a los ensayos 
académicos que se enfocan con especial atención al estudio del cuerpo jurídico/literario y de aquellos personajes que no se inscriben en los estándares que el ordenamiento jurídico plantea. Al mismo tiempo, dentro de esta sección se analizan conceptos pertenecientes a la deontología del derecho expresados por medio de la literatura. En el artículo de Giuseppa Ottimofiore se permite al lector adentrarse en el verdadero alcance y limitaciones del término utopía esbozado por Tomás Moro. El trabajo de Diego Falconí Trávez no puede pasar desapercibido. En este, el complejo entramado conceptual orienta la discusión hacia un tema que levanta susceptibilidades dentro de nuestra sociedad: el cuerpo del delito representado a través de la hembra y del marica. La valentía del texto permite al lector comprender a través de la literatura las transgresiones cometidas por estos sujetos y sus repercusiones. Para finalizar, el artículo de Fabián Corral aborda de manera breve la relación entre el derecho y la literatura admitiendo que "novelas, crónicas y tstimonios son la negación del derecho" (p. 399).

Tal vez sea certero afirmar que la lectura del volumen editado por Diego Falconí Trávez requiere en cierta medida de lectores especializados. Efectivamente, comprender los intertextos empleados demanda un interés tanto en el derecho como en la literatura y en la filosofía. A medio camino. Intertextos entre la literatura y el derecho revela como personaje principal al lenguaje. Un lenguaje transgresor que no vacila en tocar puntos sumamente delicados, casi hasta innombrables, en nuestras sociedades, todavía hoy en día conservadoras. Asimismo, resulta menester reconocer la importancia del género, el rol del cuerpo y de los sujetos, y el empleo del intertexto en el conjunto de la obra.

Probablemente, las reflexiones más profundas del derecho provienen de la narrativa de grandes maestros de la literatura como Kafka, Dostoievski, Shakespeare, entre otros. De la pluma de estos autores ha sido posible experimentar las injusticias de determinadas épocas, las normas que rigen a las sociedades y los sujetos que pueden actuar como agentes jurídicos en los diversos momentos históricos. Historias que si bien son meras representaciones de una realidad determinada, logran transmitir al lector cierta duda respecto del manejo de la justicia y del rol del magistrado, del legislador y de todos aquellos involucrados en el mundo de los sistemas jurídicos que, como los lingüísticos, son sistemas normativos.

Son por estas razones que cada ensayo académico esbozado a lo largo de este volumen permite al lector cuestionarse dogmas intocables que han sido inculcados por el derecho. Poco más que eso se le puede pedir a la Academia. La literatura, en estos casos, parece constituir una herramienta o foro que dota de validez a críticas enfocadas a mejorar el mundo del orden, de la normatividad, de la permisión y la prohibición: el mundo del derecho. Este libro no busca dar respuestas; al contrario, busca generar dudas en el lector. Dudas que se encuentran a medio camino y cuya resolución acaso se encuentre tanto en el derecho como en la literatura.

\section{Referencias Bibliográficas}

Binder, G., y Weisberg, R. (2000). Literary Criticism of Law. New Jersey: Princeton University Press.

Crane, G., Gelpi, A., y Posnock, R. (2002). Cambridge Studies in American Literature and Culture: Race, Citizenship, and Law in American Literature. Cambridge, UK: Cambridge University Press.

Culler, J. (2000). Breve introducción a la teoría literaria. Barcelona: Editorial Crítica.

Dostoiewski, F. (2009). Los hermanos Karamazov. 6a Ed. Barcelona: Editorial Juventud,

Eagleton, T. (1998). Una introducción a la teoría literaria. México D.F.: Fondo de Cultura Económica.

Falconí Trávez, D. (2016). A medio camino. Intertextos entre la literatura y el derecho. Valencia: Tirant Humanidades. 
- (2013). Las entrañas del sujeto jurídico. Un diálogo comparatista entre la literatura y el derecho. Quito: Cevallos Editora.

Gary, R. (2005). Western Law, Russian Justice: Dostoevsky, the Jury Trial, and the Law. Wisconsin: University of Wisconsin Press,.

Genette, G. (1989). Palimpsestos. La literatura en segundo grado. Madrid: Taurus.

Heinzelman, S. (2013). The Cultural Lives of Law: Riding the Black Ram: Law, Literature, and Gender. California: Stanford Law Bookds.

Kafka, F. (2004). El proceso. Madrid: Valdemar.

Polloczek, D. P. (1999). Literature and Legal Discourse: Equity and Ethics from Sterne to Conrad. Cambridge, UK: Cambridge University Press.

Posner, R. A. (1986). Law and Literature: A Relation Reargued. Virginia Law Review, 72 (8), 1351-1392. https://doi.org/10.2307/1073042

Salmond, J. W. (1922). The Literature of Law. Columbia Law Review, 22 (3), 197-208.

Seaton, J. (1999). Law and Literature: Works, Criticism, and Theory. Yale Journal of Law \& the Humanities, 11 (2), 479-507. https://doi.org/10.2307/1112220

Selden, R. (2000). La teoría literaria contemporánea. Barcelona: Editorial Ariel. 